\title{
The Influence of Service Usefulness of Community Children's Centers of Problem Solving Abilities Mediated by Self-Esteem for Low-Income Families
}

\author{
In Kim, Woong-Soo Kim, Seong-Chan Bae
}

\begin{abstract}
The purpose of this research was to examine the level of community child center help service influence to children in low-income with regards to their problem solving ability and to measure the relationship of its effect to the child's self-esteem.

This research used a nationwide surveyed data of community child center surveyed by Panel Study on Korean Children and was analyzed using a structural modeling. The survey was conducted in 2016 from July to August, survey questionnaires were sent to different community child center nationwide, the subjects were elementary 4th graders, and survey garnered 662 respondents. All this analysis were done using SPSS ver.21 and AMOS ver.21 program.

The research results were the following. First, it shows that the higher the level of community child center help service to children in low-income the child's problem solving ability goes high. Second, as the community child center help service increases the child's self-esteem increases as well. Third, it shows that as self-esteem increases the problem solving ability goes high. Fourth, it also shows that the relationship of the effect between community child center help service to child in low-income and problem solving ability were statistically significant both total and indirect effect. Furthermore, it shows that relationship of community child center help service to child in low-income and problem solving ability has a mediating effect to child self-esteem.

Base on this result, we propose that a better convergence of intervention and practical strategy must be impost to continue the betterment of child in low-income's problem solving abilities.
\end{abstract}

Keywords : children in low-income, community child center, problem solving ability, self-esteem, child welfare.

\section{INTRODUCTION}

According to UN Convention on the Rights of the Child on the ground of growth and development process, all children must be guaranteed to receive the following rights to survive, protection, development and participation. The International Convention on the Rights of the Child had made diversified policy and actions to look into the betterment of child's quality of life, they were interested and

Revised Manuscript Received on July 22, 2019.

Woong-Soo Kim, Hanil University, Korea. Email: holyws@ gmail.com

In Kim, Hanil University, Korea. Email: inkim65@hanil.ac.kr

Seong-Chan Bae, Hanil University, Korea. Email: bae007@ hanil.ac.kr

made effort in aiming to build the best environment where a child can grow healthy and protected[1]. However, in the case of children in low-income the difficulty starts primarily in satisfying their utmost desire, because of this the child's growth and development declined and get influence into problematic behavior[2]. The 1997 IMF(International Monetary Fund) crisis in Korea and 2008 Financial crisis in the world has made wide spread polarization effect in socioeconomic that leads to the increased of poverty and high level of broken families and problems in the society. Especially, because of family's economic problems parents had to do double job that leads to the increase of run away, divorce, eventually the child is raise either by a single parent or with the grandparents. We can see that children in low-income family had experience deficient in economic and emotional support from their parents compared to children who were nurtured in stable environment[3]. When a child experienced a poverty in their growth process this can lead to designation to the overall development of the child. Thus, the need to provide diversified education and community service for the children in low-income in the local community has become the instrument to the establishment of community child center that takes care and support its after school care program.

For the benefit of children in low-income the community child center made them the first priority in the community to get the support from child welfare services. In December 2016, there are about 106,668 children benefited the Korean community child center in 4,107 location throughout Korea[4]. These children who were benefiting these community child centers were mostly coming from either low socioeconomic or living in a poor parenting environment. Children in low-income has improve their problem solving ability while in the community child center and it also shows that their everyday life and school adjustment were significantly high[5]. The community child center has been doing its best effort to provide children an after school care, school related educational service, cultural experience service, child's psychological and emotional support plus diversified element of services needed for child's development. With this kind of services provided by community child center it 
shows a positive influence to children with regards to child's ability empowerment and psychological social adaptation[6, 7].

However, if the children in low-income life gets affected by negative influence due to a poor nurturing attitude of the parents, the child may experience psychological and emotional difficulties [8].

Children in low-income needs a problem solving ability that can overcome problem and handle the problem with ease if problem arises in a given situation. Problem solving ability is a skill in finding effective ways to handle problems that we encounter in our everyday life and overcome them with ease[9]. As people live by, we may encounter different kind problems regardless of intention, there are easy and simple problem but there are also complex and difficult problems. However, people with high problem solving ability can overcome problem and solve the problem calmly when crisis situation arises. Problem solving ability is one of the childhood abilities one must acquire in individual process of development to be able to form a positive peer relationship, this will enable the child to individually and in group to adapt positively. Investigative studies are needed to fully understand the relationship between problem solving ability and children in low-income who had received the community child center services. This research study is to examine whether or not the level of community child center help service to children in low-income can effectively improve the problem solving ability and be able to overcome problems in any situation calmly, the result of this study will determine whether the community child center and child welfare service plays important role in the children in low-income's growth and development.

In addition, problem solving ability when there is a crisis occurred in a situation it can find an affirmative meaning efficiently that requires coping with psychological and emotional aspect, this role can be played by self-esteem. Self-esteem means valuing oneself, so the higher the self-esteem, the higher the problem solving ability of oneself. Self-esteem is perceived to be a skill because it makes one's behavior to act right, able to control, adjust and adapt in any circumstances[10]. Children with high self-esteem tends to perform positively in many ways, can easily cope and overcome positively when confronting problems in a given situation.

Finally, self-esteem played important role as protective factor and strengthening the problem solving ability of children in low-income to be able solve problem in a given situation[11]. But even to this date there is insufficient research studies that investigate the relationship between community child center help service to children in low-income, self-esteem and problem solving ability. On this research we would like to draw our various complex of intervention and action plan strategy that will improve the problem solving ability of children in low-income family.

\section{MATERIALS AND METHODS}

\section{A. Research Target and Collecting Survey}

This research utilizes the surveyed data from community child center surveyed by Panel Study on Korean Children. The data samples were taken from National Youth Policy Institute in 2011 where the subjects were youth from vulnerable social group, and in 2013 the National Youth Policy Institute commissioned the Ministry of Health and Welfare and the Headquarters for Community Child Center to survey the community child center's beneficiaries with regards to their individual development, environmental development and other usage of the centers. The survey was conducted in 2016 from July to August, survey questionnaires were sent to different community child center nationwide, the subjects were elementary 4th graders, and survey garnered 662 respondents.

\section{B. Research Methods}

This research utilizes the measurement of scale developed by National Youth Policy Institute to measure the dependent variable which is problem solving ability and independent variables Community Child Center help service, Ministry of Health and Welfare and Headquarters for Community Child Center. It also utilizes data from Panel Study on Korean Children. There were 8 variable questions in problem solving ability, 9 variable questions in community child center help service which can be measured in 5 points Likert scale. While there were 10 variable questions for self-esteem with the measurement developed by Rosenberg[12] with a 5 points Likert scale as mediation.

\section{Date Analysis}

In this research we implemented the following statistical methods to see the mediating effect of self-esteem to community child center help service and to see the influence of children in low-income's problem solving ability. First, to examine the characteristic of the subjects and the characteristic of each variables a frequency and descriptive analysis was applied. Second, to construct a Latent variable, factor analysis was executed using the observed variables. Third, base on the confirmatory factor analysis we able to analyze the research model using the structural model analysis, we also executed a bootstrapping to obtain the statistically significant of total effect and indirect effect of the model. To identify suitability of model, goodness of fit index including CFI(Comparative Fit Index), TLI(Turker-Lewis Index) and RMSEA(Root Mean Square Error of Approximation) was used. From the structural model we verified the model fit and the path coefficient. To identify the relevance of the model, goodness of fit index including CFI(Comparative Fit Index), TLI(Turker-Lewis Index) and RMSEA(Root Mean Square Error of Approximation) was used. All this analysis were done using SPSS ver.21 and AMOS ver.21 program.

\section{RESULTS AND DISCUSSION}




\section{A. Characteristics of the Subjects}

The respondents were categorically divided into $337(50.9 \%)$ were female students, and $325(49.1 \%)$ were males. About $62.3 \%$ of the respondents living in the family with their biological parent while $37.7 \%$ of the respondents living with other than member of the family live together. About 53.6\% of the respondents belong to a family with economic difficulty keeping the standard of living, while about $40.8 \%$ belong to ordinary standard of living. The respondents of this research if compared to other community child center the ratio of children in low income family is much higher Table 1

Table 1: Characteristics of the Subjects

\begin{tabular}{|c|c|c|c|}
\hline variables & category & number & percentage \\
\hline \multirow{2}{*}{ gender } & male & 325 & 49.1 \\
& female & 337 & 50.9 \\
\hline \multirow{3}{*}{ family form } & prenatal & 412 & 62.3 \\
& parents & 250 & 37.7 \\
& step parents & & 37.0 \\
\multirow{2}{*}{ economic } & very bad & 245 & 16.6 \\
Level & bad & 110 & 40.8 \\
& average & 270 & \\
\hline
\end{tabular}

\section{B. Characteristics of Major Variables}

To check for the normality of residuals we calculated the measurement value of every variables for its level of skewness and kurtosis. In Table 2 shows the result of the characteristics of major variables. Normally, if the value of the standard deviation is bigger than the absolute value of 3.0 then there is problem with distribution [12]. Our research result shows that dependent variable problem solving ability has a mean value of $3.40(\mathrm{SD}=.78)$ while our mediator variable self-esteem has a mean value of 3.22( $\mathrm{SD}=.61$ ), and our independent variable community child center help service has a mean value of 4.04( $\mathrm{SD}=.79)$, it appears that our community child center help service is a bit high in this aspect.

Table 2: Characteristics of Major Variables

\begin{tabular}{|c|c|c|c|c|c|c|c|}
\hline $\begin{array}{c}\text { variable } \\
\text { S }\end{array}$ & number & min & max & mean & S.D. & S.K. & K.U. \\
\hline $\begin{array}{c}\text { Service us } \\
\text { efulness }\end{array}$ & 662 & 10 & 5.0 & 4.04 & .79 & -.751 & .706 \\
\hline $\begin{array}{c}\text { self-esteem } \\
\text { problem }\end{array}$ & 662 & 1.25 & 4.0 & 3.22 & .61 & -.405 & -.615 \\
\hline $\begin{array}{c}\text { solving } \\
\text { ability }\end{array}$ & 662 & 1.0 & 5.0 & 3.40 & .78 & -.303 & .262 \\
\hline
\end{tabular}

\section{Analysis of Structure Model}

Child's problem solving ability an in-deep verification analysis of the structural model in was conducted. The result show in Table 3 and Table 4. The result of the structural model shows a $\chi 2$ (Chi-square) of 146.626 with a p-value $(p<.001)$, TLI value of .961 , and CFI value of .970 , with RMSEA of .053 confirming that we have a goodness of fit in our structural model. Statistical analysis shows that the higher community child center help service the higher the that self-esteem increases with a value of $(.086, \mathrm{p}<.001)$. problem solving ability increases $(.115, \mathrm{p}<.001)$, it also shows

Furthermore, it shows that the higher self-esteem the higher the problem solving increases as well with a value of $(.219$, $\mathrm{p}<.05)$.

Table 3: Correlation among Major Variables

\begin{tabular}{|c|c|c|c|c|c|}
\hline Model & $\mathbf{X}^{2}(\mathbf{d f})$ & p-value & CFI & TLI & RMSEA \\
\hline measured model & 146.626 & .000 & .970 & .961 & .053 \\
\hline
\end{tabular}

Table 4: Result of measurement model analysis

\begin{tabular}{|c|c|c|c|}
\hline Variable & Estimate & S.E & C.R \\
\hline $\begin{array}{c}\text { service usefulness } \rightarrow \text { problem } \\
\text { solving ability }\end{array}$ & $.115(.155)$ & .035 & $3.327^{* * *}$ \\
\hline service usefulness $\rightarrow$ self-esteem & $.086(.218)$ & .019 & $4.523^{* * *}$ \\
\hline $\begin{array}{c}\text { self-esteem } \rightarrow \text { problem solving } \\
\text { ability }\end{array}$ & $.219(.116)$ & .093 & $2.350^{*}$ \\
\hline \multicolumn{4}{|c}{${ }^{*}<.05,{ }^{* * *} \mathrm{p}<.001$}
\end{tabular}

The measurement Model among all the latent variables through in Figure 1 showed significance. The result showed that the mediator effect of self-esteem was statistically significant.

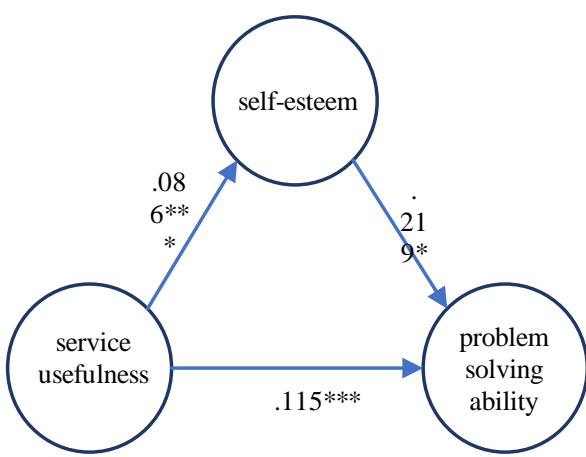

Fig. 1: Model of mediating effect

Base on statistical result of the structural model we carried out an effect analysis model. The result is shown in Table 5. The calculation of the significant value of the total effect and indirect effect were done using the method of bootstrapping 1000 times. The result of bootstrapping shows the level of influence of community child center help service towards problem solving ability has found that the total effect was statistically significant while self-esteem also shows indirect effect was statistically significant; we confirmed that self-esteem has a partial mediation effect.

Table 5: Effectiveness analysis
\begin{tabular}{|c|c|c|c|}
\hline channel & direct effect & indirect effect & total effect \\
\hline measured model & 146.626 & .000 & .970 \\
\hline p $<.05, \quad{ }^{* * * *} \mathrm{p}<.001$
\end{tabular}

\section{CONCLUSION}

This research has applied the structural modeling analysis to analyze the influence of mediating effect of self-esteem between the level of community child center help service and problem solving ability. The result of the investigation has found that although the level of community child center help service to children in low-income has a direct effect of influence however even with a mediator it also found to have indirect effect. Base on the result we had confirmed that 
self-esteem has partial mediating effect.

We are going to discuss the key findings and suggestion in this research. First, it shows that community child center help service has significant influence on children in low-income's problem solving ability. This is a confirmed result that the lack of family, neighborhood and school support to children in low-income's various needs were considered important desire for support from community child center. More so, that the community child center services to children in low-income on their proper care, counseling, and friend relationship formation had shown high adaptability in family and in school. With this respect, community child center is a society, culture, and education because it provides a network of various care and welfare services to marginalize children based on community trust and solidarity.

It is vital for children in low-income that community child center's various care support will prevent them to be in a dangerous environment, rather be in a positive interaction that will provide good experiences and promotes development of individual abilities. Therefore, the community child center must continue to develop multifaceted program so that children in low-income family can positively experience educational program and be able to cope the problems active attitude and improve their skills. Second, the investigation found the mediating effect of self-esteem between problem solving ability and community child center help service to children in low-income family. In this aspect as self-esteem increases problem solving ability increase as well. Furthermore, a surveyed had found that children in low-income were more likely to have high self-esteem and have positive effect on problem solving ability when they received help from community child center. When we consider the finding of this research, the support of community child center to children in low-income family can inhance their self-esteem into much higher and they will be able to cope up with solving problem in crisis situation. Children with high self-esteem are more likely to accept and respect themselves and can actively cope up in solving problems. Based on this research result, it is necessary to create a service and program intervention that can enhance the self-esteem of children who are using the community child center. However, the respondents' average self-esteem has been surveyed to be moderate. This is because there many children in low-income families using the community child center. Compared to normal children, children in low-income family more likely to have low in self-confidence due to vulnerable environment. The community child center should continue to enforce the need to develop an active program that will improve self-esteem and matches the characteristic and needs of children in low-income families. Additionally, because the after-school care was only given to children who are belong to children in low-income who avail the used of community child center therefore this service must expand to a universal and comprehensive child service.

This research has some limitations. First, the selection of the research subject, the research only selected elementary students as respondents this can occur limitation to the generalization of the result, the necessity to carefully interpret the result is highly needed. Another occurred limitation is that the various variables in child's problem-solving ability were not all considered with significant effect. With these limitations it is highly needed a continues research on children's usage of community child center depending on child's age in order to know the difference, there is a need to know, how the personality factor and social factor would have a mediating effect to problem solving ability depending on their age. In this course it is necessary in the future that community child center create more comprehensive suggestions to develop programs and services for those in need.

\section{REFERENCES}

1. Kim WS, “A Study on Children's Rights and Happiness for Building Child Friendly Cities: Comparative study between elementary and middle school students," Journal of Digital Convergence, 15(2), pp. 485-491, Feb. 2017. DOI:10.14400/JDC.2017.15.2.485.

2. Park RG, Kang WS, "Emotional and Behavioral character of low-Income class Children," Korean Journal of Child Psychotherapy[Internet], 1(1), 1-23, Mar. 2006. [cited 2018 Sep 15]; Available: http://scholar.dkyobobook.co.kr/searchDetail.laf?barcode $=40500252621$ 25\#.

3. Moon AR, Lee YH, "Development Plan of the Education Welfare Policy for Children and Adolescents of Low Income Group," Journal of Digital Convergence, 16(3), pp. 333-344, Mar. 2018 DOI:10.14400/JDC.2018.16.3.333.

4. Headquarters for Community Child Center. [Image on internet]. 2016 [updated 2016 Dec 31; cited 2018 Sep 15]. Available: https://www.icareinfo.go.kr/intro/center/centerAboutus.do?menuNo=200 4300(website) .

5. Kim SH, Yim HR, Chung IJ, "The Effects of Satisfaction with the Service from Community Child Centers on Children's School Adjustment Mediated by Study Habit and Peer Attachment," Journal of School Social Work[Internet], 37, pp. 119-146, Mar. 2017[cited 2018 Sep 16]; Available :http://kiss.kstudy.com/ thesis/thesis-view.asp?key=3572005.

6. Lee ES, Lee SY, Hong SH, "The Effects of Community Child-Center Service on School Adjustment Change Trajectory: Using Second-Order Latent Growth Model' Korean Journal of Social Welfare Research, 50, pp. 59-85, Sep. 2016, DOI:10.17997/SWRY.50.1.3.

7. Kim HS, Seo Y, "The Effect of the Support of the Community Child Center on Children's Happiness: The analysis on multi-groups of mediating effects of self-esteem and resilience of children with a single parent and children with two parents," Journal of Youth Welfare, 19(4), pp. 1-24. Dec. 2017, DOI:10.19034/KAYW.2017.19.4.01

8. Han AR, “The Influence of Parents' Neglect and Abuse, Service Usefulness of Community Children Center on Adolescents' Life Satisfaction in Low Income Family: Mediating Effect of Self-resilience," Korean Journal of Youth Studies, 24(7), pp. 29-54. Jul. 2017 DOI:10.21509/KJYS. 2017.07.24.7.29

9. Jung JY, H EG, "The Effect of Social Support and Problem solving Ability of Low-Income Divorced Family`s Children on Problem Behavior,' Korean Journal of Human Ecology[Internet], 16(3), pp. 491-504, Jun. 2007[cited 2018 Sep 16]. Available: http://www.dbpia.co.kr/Journal/ArticleDetail/NODE02346238

10. Lee JS, Han HS, "The effect of personality trait and psychological family environment on social problem-solving abilities for middle school student: The mediating effect of self-esteem and peer relationship skills," Korean Journal of Child Psychotherapy[Internet], 11(3), pp.1-23, Dec. 2016[cited 2018 Sep 20];. Available: http://scholar.dkyobobook.co.kr/searchDetail.laf?barcode=40500252632 05

11. Koruklu N. Personality and social problem-solving, "The mediating role of self-esteem. Educational Sciences," Theory \& Practice, 15(2), pp. 481-487, Nov. 2015. DOI: 10.12738/estp.2015. 2.2601.

12. Rosenberg M, Society and the adolescent self-image, Princeton University Press. 1965. 


\section{AUTHORS PROFILE}

In Kim 1988 : Yunsein Univ. Social Welfare(B.A)

1994: Soongsil Univ. Social Assistance(M.A)

1999: Soongsil Univ. Social Welfare(Ph.D)

2001 Present : Hanil Univ. Social Welfare Professor

Interests : social welfare administration, policy .

E-Mail : inkim65@hanil.ac.kr

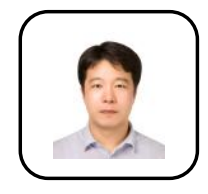

Woong-Soo Kim .2001: Hanil Univ. Social Welfare(B.A)

2003: Soongsil Univ. Social Assistance(M.A)

2007: Bremen Univ. Social Welfare(Ph.D)

2008 Present : Hanil Univ. Social Welfare Professor Interests : Youth Welfare, Correction Welfare, E-Mail : holyws@hanil.ac.kr

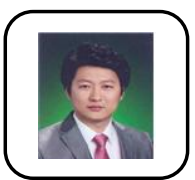

Seong-Chan Bae .2000 : Seonam Univ. Department of Computer Information(B.S)

2002 : Seonam Univ. Department of Computer Information(M.S)

2006 : Hanil Univ. Faculty of Theology(M.Div)

2013 : Seonam Univ. Social Welfare(Ph.D)

2009 Present : Hanil Univ. Social Welfare Professor

Interests : Multicultural,, Child welfare,

E-Mail : bae007@hanil.ac.kr 